\title{
Cost reduction in left ventricular assist device therapy: An elusive paradigm
}

\author{
Murray H. Kwon, MD, MBA
}

\footnotetext{
From the Division of Cardiac Surgery, Department of Surgery, David Geffen School of Medicine at UCLA, Los Angeles, Calif.

Disclosures: Author has nothing to disclose with regard to commercial support.

Received for publication Jan 22, 2018; accepted for publication Jan 30, 2018; available ahead of print March 8, 2018.

Address for reprints: Murray H. Kwon, MD, MBA, 10833 Le Conte Ave, CHS 62-229, Los Angeles, CA 90095 (E-mail: mkwon@ymail.com).

J Thorac Cardiovasc Surg 2018;155:2469-70

$0022-5223 / \$ 36.00$

Copyright (c) 2018 by The American Association for Thoracic Surgery

https://doi.org/10.1016/j.jtcvs.2018.01.051
}

As we recently celebrated the 50th anniversary of heart transplantation, it is hard to imagine few areas of medicine as captivating as the replacement of the failing human heart. Although transplantation has seen few advances during the past several decades, ventricular assist devices (VADs) have undergone monumental evolutions during the same interval. ${ }^{1}$ They represent the latest technology and offer hope to patients when none other exists. The elephant in the room, however, is that although the devices offer incredible benefit at the individual patient level, the cumulative societal benefit of the technology, given its exorbitant costs, remains unknown.

In their article in this issue of the Journal, "Reducing the Cost of Left Ventricular Assist Devices: Why It Matters and Can It Be Done?' Shih and colleagues ${ }^{2}$ do an excellent job of putting the first question into perspective. For the uninitiated, they give an excellent primer on the concepts of quality-adjusted life years and incremental costeffectiveness ratios, and they discuss how VAD therapies compare with optimal medical management. The $\$ 209,400$ per quality-adjusted life year cost attributed to VADs in patients not dependent on inotropes receiving VAD destination therapy is contrasted with the aforementioned medical therapies, which range from $\$ 3700$ for angiotensin-converting enzyme inhibitors to $\$ 60,000$ for automatic implantable cardioverter-defibrillators.

The fact that decisions regarding VAD therapies are based on clinical assessments and do not factor in cost is well known but important to reiterate. The public's abhorrence of the concept of "death panels" has rendered the idea of using strict cost per quality-adjusted life year thresholds to help determine appropriate therapies infeasible. Without responsible usage of our financial resources in health care, however, it is hard to imagine that expensive therapies such as VADs will not have particularly deleterious consequences in the aggregate. Despite spending the highest amount per capita on health care, the United States lags well behind its peers in life expectancy at birth. ${ }^{3}$ As

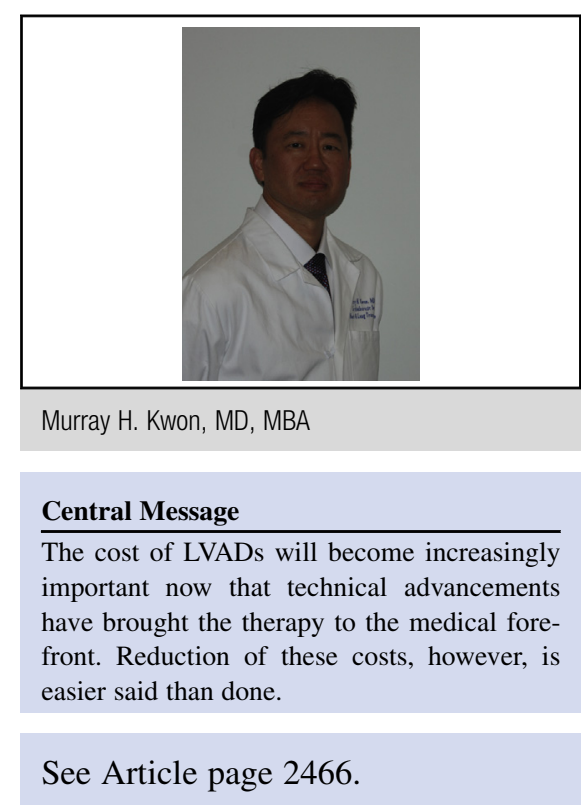

also stated in the article, ${ }^{2}$ the high cost of LVAD therapy must be overcome if we are to appreciate its widespread adoption.

The answer to the second question- "Can it be done?"-is thus much more elusive. Although the proposed solutions of decreasing readmissions, increasing outpatient surveillance, and relying on technical advances seem sensible, their realization is anything but straightforward. For example, the allure of the latest generation HeartMate 3 device (St Jude Medical, St Paul, Minn) is the absence of pump thrombosis during its early clinical trials. ${ }^{4}$ Few of us believe, however, that this will be a driving force in future cost reductions.

What is unique to the VAD market is that it is virtually a duopoly, with the two major players jockeying for incremental value added with each successive generation of its devices. The high barriers to entry into this field make it unlikely that this dynamic will soon change, yet it is one of the inherent reasons behind the high cost of VAD therapy in general. ${ }^{5}$ Stifling competition with increased regulation is not my assertion. However, while we all agree wholeheartedly with the article's premise that cost matters, the resolution is extremely complicated and unlikely to lie in readmissions and technology advancements alone.

\section{References}

1. Csepe TA, Kilic A. Advancements in mechanical circulatory support for patients in acute and chronic heart failure. J Thorac Dis. 2017;9:4070-83. 
2. Shih T, Dimick JB. Reducing the cost of left ventricular assist devices: why it matters and can it be done? J Thorac Cardiovasc Surg. 2018;155:2466-8.

3. Squires D, Anderson C. U.S. health care from a global perspective: spending, use of services, prices, and health in 13 countries. Issue Brief (Commonw Fund). 2015;15:1-15.

4. Uriel N, Colombo PC, Cleveland JC, Long JW, Salerno C, Goldstein DJ, et al. Hemocompatibility-related outcomes in the MO-
MENTUM 3 trial at 6 months: a randomized controlled study of a fully magnetically levitated pump in advanced heart failure. Circulation. 2017; 135:2003-12.

5. Kesselheim AS, Avorn J, Sarpatwari A. The high cost of prescription drugs in the United States: origins and prospects for reform. JAMA. 2016;316: 858-71. 